\title{
Effect of humic acid coating on arsenic adsorption on ferrihydrite-kaolinite mixed systems
}

\author{
M. Martin ${ }^{1,2}$, L. Celi ${ }^{2}$, E. Barberis ${ }^{2}$, A. Violante $^{3}$, L. M. Kozak ${ }^{1}$, and P. M. Huang ${ }^{1,4}$ \\ ${ }^{1}$ Department of Soil Science, University of Saskatchewan, 51 Campus Drive, Saskatoon, Saskatchewan, Canada \\ S7N 5A8; ${ }^{2}$ Università di Torino, DI.VA.P.R.A. - Chimica Agraria, Via L. da Vinci 44, 10095 Grugliasco (TO), Italy; \\ and ${ }^{3}$ Università di Napoli Federico II, Dipartimento di Scienze del suolo, della pianta, dell'ambiente e delle \\ produzioni animali, Via Università, 100-80055, Portici (NA), Italy. Received 30 August 2008,
} accepted 24 February 2009.

\begin{abstract}
Martin, M., Celi, L., Barberis, E., Violante, A., Kozak, L. M. and Huang, P. M. 2009. Effect of humic acid coating on arsenic adsorption on ferrihydrite-kaolinite mixed systems. Can. J. Soil Sci. 89: 421-434. The reactivity of the colloids formed in soil environments results from complex interactions between clay minerals, (oxy)hydroxides and organic matter of soils. The adsorption/desorption equilibria and kinetics of anionic and cationic species on/from natural colloids could substantially differ compared with their interaction with pure minerals. The objective of this study was to investigate the arsenite and arsenate equilibria and the kinetics of arsenite adsorption on ferrihydrite-coated kaolinite as influenced by the presence of humic acid coverage. The Langmuir adsorption maximum and affinity of arsenite and arsenate adsorption on the kaolinite-ferrihydrite system was reduced by the presence of the humic acid. The enthalpy of adsorption on the kaolinite-ferrihydrite system, measured with isothermal titration calorimetry, was $-24.4 \mathrm{~kJ} \mathrm{~mol}^{-1}$ for arsenite and -39.9 $\mathrm{kJ} \mathrm{mol}^{-1}$ for arsenate, and was only slightly decreased by the humic acid coating. The kinetics of arsenite adsorption was substantially influenced by the presence of the humic coverage, resulting in the decrease in the rate constant, the Arrhenius heat of activation, and the pre-exponential factor (indicative of the collision frequency of the sorbate and the sorbent). The hampering effect of the humic acid on arsenic adsorption was attributable to the blocking by the organic ligand of the adsorbing sites, coupled with the steric hindrance of the large organic molecules, which restricted the arsenic to approach the surfaces.
\end{abstract}

Key words: Arsenic, adsorption, kinetics, kaolinite, ferrihydrite, humic acid

\begin{abstract}
Martin, M., Celi, L., Barberis, E., Violante, A., Kozak, L. M. et Huang, P. M. 2009. Incidence de l'acide humique sur l'adsorption de l'arsenic dans les systèmes mixtes ferrihydrite-kaolinite. Can. J. Soil Sci. 89: 421-434. La réactivité des colloïdes formés dans le sol dépend des interactions complexes entre les minéraux présents dans l'argile, les (oxy)hydroxydes et la matière organique du sol. L'équilibre entre adsorption et désorption, et la cinétique des anions et des cations sur les colloïdes naturels ou qui en émanent pourraient sensiblement différer face à ce qu'on observe dans les interactions avec les minéraux purs. La présente étude devait préciser l'équilibre entre les arsénites et les arséniates ainsi que la cinétique de l'adsorption des arsénites sur de la kaolinite enduite de ferrihydrite en présence d'une couche d'acide humique. L'acide humique réduit le maximum d'adsorption de Langmuir et l'affinité des arsénites ainsi que l'adsorption des arséniates dans le système kaolinite-ferrihydrite. Mesurée par calorimétrie à titrage isotherme, l'enthalpie de l'adsorption dans le système kaolinite-ferrihydrite s'établit à $-24.4 \mathrm{~kJ}$ par mole pour les arsénites et à $-39,9 \mathrm{~kJ}$ par mole pour les arséniates; la couche d'acide humique ne la réduit que légèrement. La cinétique de l'adsorption des arsénites est sensiblement influencée par la présence d'une couche d'acide humique, ce qui entraîne une diminution de la constante de vitesse, de l'énergie d'activation d'Arrhénius et du facteur pré-exponentiel (indiquant la fréquence des collisions entre sorbat et sorbant). L'effet atténuant de l'acide humique sur l'adsorption de l'arsenic résulte du blocage des sites d'adsorption par les ligands organiques, associé au fait que les grosses molécules organiques nuisent à l'effet stérique, ce qui empêche l'arsenic d'approcher les surfaces.
\end{abstract}

Mots clés: Arsenic, adsorption, cinétique, kaolinite, ferrihydrite, acide humique

Arsenic is a toxic metalloid occurring in soil and water as a result of human activities or mobilization from natural sources (Mandal and Suzuki 2002; Smedley and Kinniburgh 2002). At relatively low As concentrations in soil and water environments, the equilibria of As between the solid phase and the solution are mainly

${ }^{4}$ To whom correspondence should be addressed (e-mail: pmh936@mail.usask.ca). controlled by adsorption/desorption reactions. Variable charged minerals such as $\mathrm{Mn}, \mathrm{Fe}$, and $\mathrm{Al}$ oxides represent the main adsorbing phases for As in soil and sediments (Barrow 1974; Livesey and Huang 1981; Oscarson et al. 1981; Sadiq 1997; De Brouwere et al. 2004).

Abbreviations: HA, humic acid; PZC, point of zero charge 
Inorganic $\mathrm{As}(\mathrm{III})$ (arsenite) and $\mathrm{As}(\mathrm{V})$ (arsenate) are the most common forms of As present in soil. Trivalent arsenic forms are reported to be several times more toxic than pentavalent ones (Styblo et al. 2000). In aerated soils, arsenite can be oxidized to form arsenate, while in reducing environments, arsenite can represent the main form (Masschelein et al. 1991). However, both As forms are often present in either reduced or oxidized environments due to their relatively slow redox transformation (Masschelein et al. 1991; Sadiq 1997; Smith et al. 1998). At natural soil and water $\mathrm{pH}$ values, arsenite mainly exist as undissociated $\mathrm{H}_{3} \mathrm{AsO}_{3}\left(\mathrm{pK}_{\mathrm{a} 1}=9.2 ; \mathrm{pK}_{\mathrm{a} 2}=12.7\right)$, while arsenate is mainly present in anionic forms as $\mathrm{H}_{2} \mathrm{AsO}_{4}^{-}$or $\mathrm{HAsO}_{4}^{2-}\left(\mathrm{pK}_{\mathrm{a} 1}=2.3 ; \mathrm{pK}_{\mathrm{a} 2}=6.8 ; \mathrm{pK}_{\mathrm{a} 3}=\right.$ 11.3) (Lide 2007).

The adsorption mechanisms of arsenate have been quite extensively studied; arsenate, like phosphate, is reported to form inner-sphere complexes on amorphous Fe and Al oxides (Sun and Doner 1996; Grossl et al. 1997; Smith et al. 1998; Sherman and Randall 2003). By contrast, the behavior of arsenite is less clear, in spite of its higher toxicity and mobility. Arsenite seems to form both inner and outer-sphere complexes on poorly ordered $\mathrm{Fe}$ oxides and outer-sphere complexes on $\mathrm{Al}$ oxides (Arai et al. 2001; Goldberg and Johnston 2001), although different possible mechanisms are proposed for the same adsorbent (Ona-Nguema et al. 2005).

The high adsorption capacity of short-range ordered Fe oxides (such as ferrihydrite) toward both arsenite and arsenate has been reported (Pierce and Moore 1982; Raven et al. 1998; Jain et al. 1999; Dixit and Hering 2003). Ferrihydrite (as well as most poorly ordered soil oxides) is often present in soils not as discrete particles, but in form of thin films which coat the colloidal particles of phyllosilicates. The coating strongly influences the mineral surface properties (Cornell and Schwertmann 1996; Celis et al. 1998), partly or completely masking the permanent negative charge of phyllosilicates (Shao and Wang 1991; Arias et al. 1995).

The interaction with soil organic matter can further modify the characteristics of the surfaces resulting from the interaction between phyllosilicate and iron oxides in natural soil colloids (Kretzschmar and Sticher 1997; Martin 2003). The amount and the fractions of soil organic matter (i.e., dissolved organic matter, fulvic acids, humic acids, and humin) interacting with the mineral components may affect the colloidal flocculation/dispersion equilibrium, the surface electrical charge, the equilibria of $\mathrm{Fe}$ between the solution and the solid phase (Martin 2003) and, consequently, the extent and mechanisms of As adsorption may be changed. Some studies have shown that the mobility of As compounds can be considerably enhanced by the presence of water-soluble organic matter of low molecular weight (Kalbitz and Wennrich 1998; Grafe et al. 2001). The presence of humic or fulvic molecules is reported to hinder As adsorption on phyllosilicates and pure oxides (Grafe et al. 2001, 2002; Cornu et al. 2003;
Simeoni et al. 2003; Bauer and Blodau 2006), although, on the other hand, humic acids could adsorb As onto positively charged amino groups (Saada et al. 2003). The chemistry of As sorption on clay-humus complexes is even less understood, especially for the trivalent form.

The objective of this work was to investigate the arsenite and arsenate equilibria and the kinetics of arsenite adsorption on kaolinite-ferrihydrite and kaolinite-ferrihydrite-humate complexes. The expected findings are of fundamental significance in understanding As interaction with a ternary system, i.e., layer silicateamorphous $\mathrm{Fe}$ oxide-humic substance complexes, which are common in soil and related environments.

\section{MATERIALS AND METHODS}

Synthesis and Characterization of the Adsorbents The humic acid (HA) was extracted and purified as described by Swift (1996) from a calcareous, silty-clayloam soil developed on recent deltaic deposits sampled in a rice field in Satkhira District, southwest Bangladesh (Martin et al. 2007). The HA obtained was equilibrated at $\mathrm{pH} 1.5$ before freeze drying. The elemental analysis $(\mathrm{C}, \mathrm{H}, \mathrm{N}, \mathrm{S})$ was performed with a CHNS analyser (NA2100 Protein, CE Instruments, Milan, Italy). The content of $\mathrm{O}$ was determined by difference on an ashfree basis. The total acidity was determined by $\mathrm{Ba}(\mathrm{OH})_{2}$ titration and the carboxyl content by $\mathrm{Ca}$ acetate, following the procedures described by Schnitzer and Gupta (1965). Phenolic OH groups were calculated by difference between total acidity and $-\mathrm{COOH}$ content.

The ratio between the absorbance at 465 and $665 \mathrm{~nm}$ $\left(\mathrm{E}_{4} / \mathrm{E}_{6}\right)$ of the HA, which is inversely related to the molecular dimensions of the humic substances and directly related to the amount of carboxyl groups, was determined as described by Chen et al. (1977). The FTIR spectrum was obtained with $\mathrm{KBr}$ pellets containing $0.5 \mathrm{mg}$ of freeze-dried HA in $200 \mathrm{mg} \mathrm{KBr}$. The spectra were run from 4000 to $400 \mathrm{~cm}^{-1}$ with a resolution of 4 $\mathrm{cm}^{-1}$ using an FT-IR NICOLET IMPACT $410 \mathrm{D}$ instrument (GMI Inc., Ramsey, MN).

The kaolinite was a standard sample of Georgia kaolinite (KGa2) (The Clay Mineral Society, Source Clay Mineral Repository). The kaolinite was previously separated by dispersion and centrifugation (Celi et al. 2003) in order to obtain a suspension with particle size $<2 \mu \mathrm{m}$. A two-line ferrihydrite was prepared according to the method of Schwertmann and Cornell (1991). The kaolinite-ferrihydrite (KGa2-Fh) mixed system was prepared by alkaline precipitation of the iron oxide from a $\mathrm{FeCl}_{3}$ solution mixed with the kaolinite suspension. The amount of $\mathrm{FeCl}_{3}$ was chosen in order to obtain an amount of $10 \%$ ferrihydrite per unit weight in the mixed system (Celi et al. 2003). The kaolinite-ferrihydrite-humate system (KGa2-Fh-HA) was prepared by adsorbing the HA on the kaoliniteferrihydrite system in order to obtain $50 \%$ of surface coverage, based on the results of preliminary adsorption 
isotherms. The humic acid was not completely soluble at $\mathrm{pH}$ below 8. To obtain the formation of a homogeneous system of kaolinite-ferrihydrite with the humic acid adsorbed on the surfaces, and to avoid the precipitation of separated organic and mineral phases, the adsorption of the HA on the mineral surfaces was carried out at $\mathrm{pH}$ 8 . The $\mathrm{pH}$ of the resulting kaolinite-ferrihydrite-humate system was then adjusted to 6.5. All the adsorbents obtained were kept in suspension and only an aliquot was freeze dried for specific surface area determination using the BET method by multi-point $\mathrm{N}_{2}$ adsorption (Sorptomatic 1900, Fisons Instruments, Milan, Italy). The point of zero charge (PZC) and the average particle size were measured by Laser Doppler Velocimetry coupled with Photon Correlation Spectroscopy with a DELSA 440 (Beckman Coulter Inc., Fullerton, CA).

\section{Arsenic Adsorption Experiments}

Arsenate and arsenite solutions at a concentration of $13.33 \mathrm{mmol} \mathrm{As} \mathrm{L}^{-1}$ were prepared by dissolving arsenate or arsenite salts $\left(\mathrm{Na}_{2} \mathrm{HAsO}_{4} \cdot 7 \mathrm{H}_{2} \mathrm{O}\right.$, or $\mathrm{NaAsO}_{2}$, J.T. Baker Chemicals Co, Phillipsburg, NJ) in $0.01 \mathrm{M} \mathrm{NaNO}$. Working solutions at different concentrations were prepared by dilution in $0.01 \mathrm{M}$ $\mathrm{NaNO}_{3}$ before use, and the $\mathrm{pH}$ was adjusted to 6.5 with $\mathrm{HCl}$. The arsenite-containing solutions were tested colorimetrically (Huang and Fujii 1996) to detect any possible oxidation to arsenate before each experiment.

To obtain the isotherms of arsenite and arsenate adsorption, suitable amounts of arsenate or arsenite solutions with concentration of $1.33 \mathrm{mmol} \mathrm{L}^{-1}$ were added to suspensions of each adsorbent in $0.01 \mathrm{M}$ $\mathrm{NaNO}_{3}$. The final concentration of the suspensions was $0.5 \mathrm{~g} \mathrm{~L}^{-1}$ and the final volume was $10 \mathrm{~mL}$. A series of eight points at increasing As concentrations (from 0 to $0.27 \mathrm{mmol} \mathrm{L}{ }^{-1}$ ) was obtained in order to reach the maximum adsorption capacity. The suspensions were equilibrated at initial $\mathrm{pH} 6.5$ for $24 \mathrm{~h}$ at $298 \mathrm{~K}$ and then filtered through Millipore membrane filters (pore size $0.1 \mu \mathrm{m})$. The amount of arsenite and arsenate in the supernatant was determined colorimetrically according to the method described by Huang and Fujii, (1996). The oxidation of arsenite to arsenate in the supernatant at the end of the adsorption experiments was tested; this detection method allows the distinction between the two species. No arsenate was found in the arsenite containing samples. The absorbance of the solution was determined by UV-VIS spectrometer (DU 650, Beckman Coulter Inc., Fullerton, CA) at $\lambda=850 \mathrm{~nm}$. The experiments were duplicated.

Isothermal titration calorimetric measurements of arsenite or arsenate adsorption on $\mathrm{KGa} 2-\mathrm{Fh}$ and KGa2-Fh-HA mixed systems and also on two-lines ferrihydrite were performed at $298 \mathrm{~K}$, with a calorimeter ITC 4200 (Calorimetry Sciences Corporation, Lindon, UT) equipped with $1.30 \mathrm{~mL}$ cells. The calorimeter cells initially contained $1.0 \mathrm{~mL}$ of adsorbent suspension and pure water in the sample and reference cell, respectively.
The concentration of the adsorbent suspension was $5 \mathrm{mg}$ $\mathrm{mL}^{-1}$ for the KGa2-Fh and KGa2-Fh-HA systems and $0.5 \mathrm{mg} \mathrm{L}^{-1}$ for the ferrihydrite. The $\mathrm{pH}$ of the suspensions was adjusted to 6.5 . Aliquots of $10 \mu \mathrm{L}$ of concentrated arsenite or arsenate solutions (in the range of 0.8 to $26.6 \mathrm{mM}$ ) at $\mathrm{pH} 6.5$ were injected into the stirred (500 RPM) sample cell using a $250 \mu \mathrm{L}$ Hamilton syringe driven by a microprocessor-controlled motor. In total, 20 injections were carried out for each experiment, with a $200 \mathrm{~s}$ equilibration time interval after each injection. The experiments were repeated at two different concentrations of the titrant solution for each adsorbent. The enthalpies of dilution of the arsenite or arsenate titrant solutions at different concentrations were measured by carrying out injection cycles in the absence of the adsorbent and subtracted in the calculation of the enthalpies of reaction of arsenite or arsenate at the corresponding concentration with the different adsorbents.

For the kinetic experiments of arsenite adsorption, suspensions of the two adsorbents, i.e., KGa2-Fh and KGa2-Fh-HA, with a final concentration of $0.5 \mathrm{~g} \mathrm{~L}^{-1}$ in $0.01 \mathrm{M} \mathrm{NaNO}_{3}$ at $\mathrm{pH} 6.5$ were prepared as described above and pre-equilibrated for $24 \mathrm{~h}$ at 288, 298, 308 or 318 K. An aliquot of arsenite solution previously equilibrated at $\mathrm{pH} 6.5$ was then added to the suspension to obtain a final As concentration of $0.04 \mathrm{mmol} \mathrm{L}^{-1}$, and the reaction vessel was immediately re-transferred to the constant temperature bath shaker controlled at $288,298,308$ or $318 \mathrm{~K}$. At intervals of $0.083,0.167$, $0.250,0.333,0.50,0.67,1,2,4,8,12$, and $24 \mathrm{~h}, 7 \mathrm{~mL}$ was rapidly pipetted from the suspension under vigorous stirring and filtered through $0.1 \mu \mathrm{m}$ (pore size) Millipore membrane filters within $15 \mathrm{~s}$. The As concentration in the filtrate was determined colorimetrically as described above. The possible oxidation of arsenite to arsenate was checked in all the cases and found to be not detectable at all temperatures. The amount of adsorbed As was calculated by the difference between the initial As concentration and the one determined in the solution at each time interval. All the experiments were run in duplicate.

The kinetic and empirical equations, including the zero-order, first-order and second-order rate equations and the Elovich equation were used to fit the arsenite adsorption data. The fit was evaluated based on the $r^{2}$, the level of significance $(P)$ and the standard error (SE). The statistical analysis of the data was done with the SPSS 12 for Windows (SPSS Inc).

\section{RESULTS AND DISCUSSION}

\section{Characterization of the Adsorbents}

The kaolinite-ferrihydrite system had a specific surface area of $59.4 \mathrm{~m}^{2} \mathrm{~g}^{-1}$, with a point of zero charge of 8.0 , and a positive $\zeta$ (zeta) potential of $+16 \mathrm{mV}$ at $\mathrm{pH} 6.5$, which was chosen for the arsenic adsorption experiments (Table 1). Comparing these data with those 
Table 1. Surface characteristics of the kaolinite-ferrihydrite (KGa2-Fh) and kaolinite-ferrihydrite-humate (KGa2-Fh-HA) systems

\begin{tabular}{lccc}
\hline & Ferrihydrite & KGa2-Fh & KGa2-Fh-HA \\
\hline Specific surface area & $295 \pm 1.0^{\mathbf{z}}$ & $59.4 \pm 0.9$ & $34.9 \pm 1.8$ \\
$\left(\mathrm{~m}^{2} \mathrm{~g}^{-1}\right)$ & & & \\
Average pore diameter $(\mathrm{nm})$ & $2.8 \pm 0.1$ & $23.5 \pm 0.7$ & $19.8 \pm 8.2$ \\
PZC & $8.3 \pm 0.4$ & $8.0 \pm 0.2$ & $3.8 \pm 0.4$ \\
$\zeta$ potential $(\mathrm{pH} 6.5)(\mathrm{mV})$ & $+21 \pm 3$ & $+16 \pm 4$ & $-22 \pm 2$ \\
Particle size (pH 6.5) $(\mu \mathrm{m})$ & $1.6 \pm 0.5$ & $1.0 \pm 0.2$ & $1.0 \pm 0.3$ \\
\hline
\end{tabular}

${ }^{\mathrm{z}}$ Standard deviation.

obtained for kaolinite (Celi et al. 2003) and ferrihydrite (Table 1), the association led to a system with a surface area and a point of zero charge dominated by the iron oxide and a particle shape and size governed by that of the phyllosilicate (Celi et al. 2003).

The humic acid (Table 2) showed a high degree of oxidation, as deduced by the $\mathrm{O}(39.86 \%)$ and $\mathrm{O}: \mathrm{C}$ ratio values, a prevalence of the aliphatic component, related to the $\mathrm{H}$ and the $\mathrm{H}: \mathrm{C}$ atomic ratio (Andreux 1996), and high incorporation of proteinaceous residues (N 5.37\%) (Schinitzer 1978; Tan 2003). The abundance of oxygenated functional groups (Table 2) was confirmed by the content of carboxyls and phenol groups. The relatively high content of carboxylic groups was, however, accompanied by a low $\mathrm{E}_{4}: \mathrm{E}_{6}$ ratio (4.4), indicating a relatively high degree of condensation and average-to-high molecular dimensions (Chen et al. 1977; Schnitzer 1978; Tan 2003). The FT-IR spectrum of the HA (Fig. 1), interpreted according to Schnitzer (1978) and Celi et al. (1997), basically confirmed the results from the chemical analyses: a large contribution of the aliphatic component $\left(\mathrm{C}-\mathrm{H}\right.$ stretching at $2930 \mathrm{~cm}^{-1}$ and at 2850 $\mathrm{cm}^{-1}$ and $\mathrm{C}-\mathrm{H}$ bending at $1454 \mathrm{~cm}^{-1}$ and $-\mathrm{CH}_{3}$ deformation at $\left.1384 \mathrm{~cm}^{-1}\right)$, carboxyl groups $(\mathrm{C}=\mathrm{O}$ stretching at $1712 \mathrm{~cm}^{-1}$ ), aromatic $\mathrm{C}$ (stretching of the aromatic $\mathrm{C}-\mathrm{H}$ at $1655 \mathrm{~cm}^{-1}$ and bending of aromatic $\mathrm{C}=\mathrm{C}$ at $1510 \mathrm{~cm}^{-1}$ ), amide II (C-N stretching at 1541 $\left.\mathrm{cm}^{-1}\right)$ and polysaccharide residues $(\mathrm{C}-\mathrm{OH}$ and $\mathrm{C}-\mathrm{O}$ bending at $1126 \mathrm{~cm}^{-1}$ and at $\left.1043 \mathrm{~cm}^{-1}\right)$. The broad peak in the 1240 to $1200 \mathrm{~cm}^{-1}$ region $\left(1224 \mathrm{~cm}^{-1}\right)$ was attributed to $\mathrm{C}-\mathrm{O}$ asymmetric stretch, $\mathrm{OH}$ deformation of $\mathrm{COOH}$ and $\mathrm{C}-\mathrm{OH}$ bending of phenols and of tertiary alcohols.

The maximum amount of HA adsorbed on the KGa2Fh system was $110 \mathrm{mg} \mathrm{g}^{-1}$, corresponding to a density of $7.9 \mu \mathrm{mol} \mathrm{m} \mathrm{m}^{-2}$ of adsorbed carboxyls, which are reported to be the main reactive groups involved in the adsorption of humic substances on soil minerals (Parfitt 1977; Schnitzer 1995; Martin 2003). Possibly, only a part of the carboxyls were bonded to the surface of the mineral, due to the difficulty of the large humic structures to allow the contact of all their functional groups with the adsorbing substrate, thus explaining the very high apparent adsorption density. The carboxyls

\begin{tabular}{lr}
\hline Table 2. Chemical characteristics of the humic acid \\
\hline \multicolumn{1}{c}{ Elemental Analysis $^{\mathbf{z}}$} \\
$\mathrm{C} \%$ & 48.56 \\
$\mathrm{~N} \%$ & 5.37 \\
$\mathrm{H} \%$ & 5.72 \\
$\mathrm{~S} \%$ & 0.48 \\
$\mathrm{O} \%$ & 39.86 \\
$\mathrm{C}: \mathrm{N}$ & 10.54 \\
$\mathrm{H}: \mathrm{C}$ & 1.41 \\
$\mathrm{O}: \mathrm{C}$ & 0.61 \\
& \\
Total acidity $\left(\mathrm{cmol} \mathrm{kg}^{-1}\right.$ ) & 617 \\
Carboxylic groups $\left(\mathrm{cmol} \mathrm{kg}^{-1}\right)$ & 431 \\
Phenolic $-\mathrm{OH}\left(\mathrm{cmol} \mathrm{kg}^{-1}\right)^{\mathbf{w}}$ & 186 \\
$\mathrm{E}_{4}: \mathrm{E}_{6}$ & 4.4 \\
\hline
\end{tabular}

$\mathbf{z}, \mathbf{x}$ All the values are expressed on an ash-free basis.

${ }^{\mathrm{z}}$ Standard deviation $<2 \%$.

${ }^{\mathbf{y}}$ The $\mathrm{O}$ content was obtained by the difference between the total weight (oven-dried basis) and the sum of C, N, H and S contents.

${ }^{\mathrm{x}}$ Standard deviation $<12 \%$.

"The phenolic group content was obtained by the difference between the total acidity and the carboxylic group content.

that did not react with the mineral surface remained free and were responsible for the shift of the PZC of the new surface toward a lower $\mathrm{pH}$ (3.8) (Table 1), close to the PZC measured for the pure humic acid, around $\mathrm{pH} 3$. The surface charge was then reversed at $\mathrm{pH} 6.5$, with a measured $\zeta$ potential of $-22 \mathrm{mV}$ (Table 1 ). The particle size of the KGa2-Fh system was not affected by the adsorption of the HA, due to dominance determined by kaolinite (Celi et al. 2003). The specific surface area of the KGa2-Fh-HA system was $41 \%$ lower than that of the KGa2-Fh before HA adsorption.

A reduction in the specific surface area of minerals after humic coverage is well documented and is attributed to a low affinity of the humic molecules for $\mathrm{N}_{2}$ adsorption (Pennell et al. 1995), to a very fine microporous structure of the humic matter $(<0.5 \mathrm{~nm})$ limiting

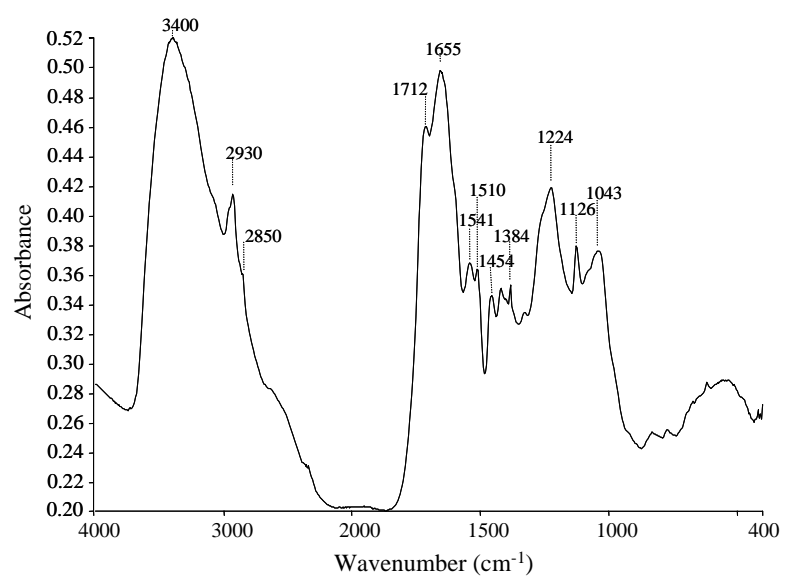

Fig. 1. FT-IR of the humic acid used in the preparation of the KGa2-Fh-HA mixed system. 
the diffusion of the $\mathrm{N}_{2}$ molecules to only the external surface of the humic matter, and to contemporary clogging the small pores of the minerals where the humic compounds were adsorbed (de Jonge et al. 2000; Kaiser and Guggenberger 2003).

\section{Adsorption Isotherms}

The adsorption isotherms at $\mathrm{pH} 6.5$ (Fig. 2) show a higher capacity of both the mixed systems to adsorb arsenite compared to arsenate and a reduced capacity of the adsorbent in the presence of the humic coverage to adsorb both arsenic species. These observations are even more evident from the Langmuir parameters for the adsorption of these As species by the fitting of the Langmuir model to the adsorption data (Table 3). The fitting was good for all the systems $\left(r^{2}>0.96\right)$, although it was better for arsenate, with $r^{2}>0.99$. At the $\mathrm{pH}$ studied, the maximum adsorption capacity $\left(\mathrm{X}_{\mathrm{MAX}}\right)$ was higher for arsenite on both the adsorbents (184.6 and $149.7 \mathrm{mmol} \mathrm{kg}{ }^{-1}$, respectively), compared with arsenate (91.0 and $77.2 \mathrm{mmol} \mathrm{kg}^{-1}$, respectively); however, the adsorption affinity constant $\left(\mathrm{K}_{\mathrm{L}}\right)$ values for the former were much lower, compared with those of the latter, indicating a lower affinity of arsenite than arsenate for the reactive surfaces. This was in agreement with the observations of Dixit and Hering (2003). The HA coating on the kaolinite-ferrihydrite system decreased both maximum adsorption capacity and affinity for

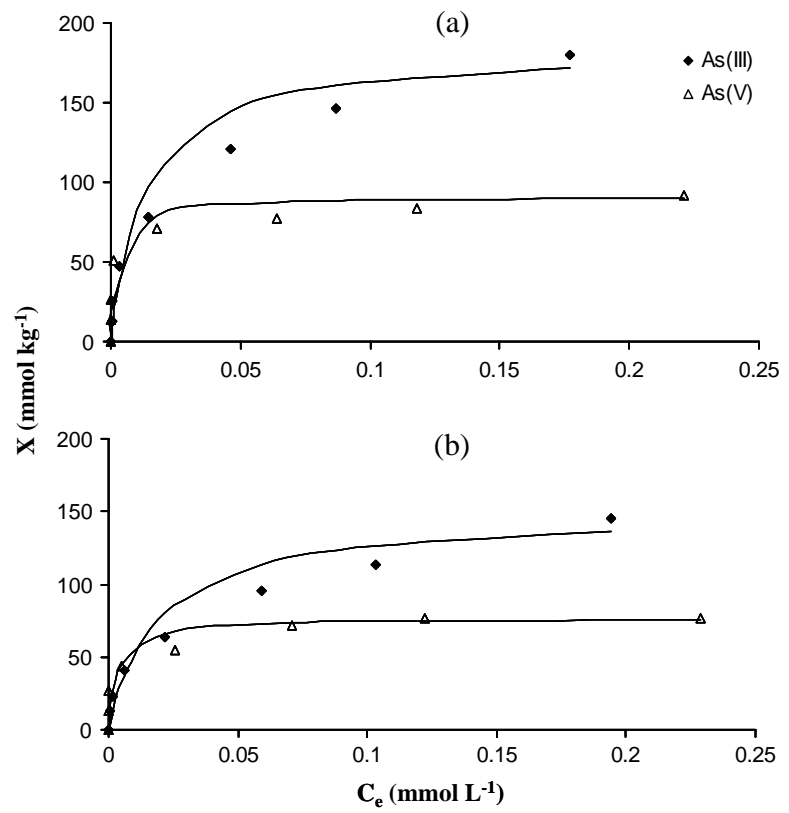

Fig. 2. Adsorption isotherms of arsenite and arsenate on: (a) $\mathrm{KGa} 2-\mathrm{Fh}$ and (b) KGa2-Fh-HA. Ce (mmol L $\left.{ }^{-1}\right)$ is the concentration of arsenite or arsenate remaining in solution at equilibrium; $\mathrm{X}\left(\mathrm{mmol} \mathrm{kg}{ }^{-1}\right)$ is the amount of As adsorbed. The lines represent the fitting of the experimental data by the Langmuir equation.
Table 3. Langmuir parameters for arsenite and arsenate adsorption on the kaolinite-ferrihydrite (KGa2-Fh) and kaolinite-ferrihydrite-humate (KGa2-Fh-HA) systems at pH 6.5

\begin{tabular}{|c|c|c|}
\hline & KGa2-Fh & KGa2-Fh-HA \\
\hline & \multicolumn{2}{|c|}{ Arsenite } \\
\hline $\mathrm{X}_{\mathrm{MAX}}\left(\mathrm{mmol} \mathrm{kg}{ }^{-1}\right)$ & $184.6 \pm 6.7^{\mathbf{z}}$ & $149.7 \pm 3.3$ \\
\hline $\mathrm{K}_{\mathrm{L}}\left(\mathrm{L} \mathrm{mol}^{-1}\right) \times 10^{-4}$ & $7.8 \pm 3.8$ & $5.3 \pm 1.5$ \\
\hline$r^{2}(20)-100$ & 0.981 & 0.969 \\
\hline$P$ & $1.7 \times 10^{-5}$ & $5.7 \times 10^{-5}$ \\
\hline \multirow{2}{*}{ SE } & $5.4 \times 10^{-5}$ & $9.4 \times 10^{-5}$ \\
\hline & \multicolumn{2}{|c|}{ Arsenate } \\
\hline $\mathrm{X}_{\mathrm{MAX}}\left(\mathrm{mmol} \mathrm{kg}{ }^{-1}\right)$ & $91.0 \pm 1.2$ & $77.2 \pm 0.4$ \\
\hline $\mathrm{K}_{\mathrm{L}}\left(\mathrm{L} \mathrm{mol}^{-1}\right) \times 10^{-4}$ & $37.8 \pm 3.2$ & $28.0 \pm 3.2$ \\
\hline 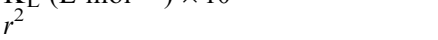 & 0.997 & 0.998 \\
\hline$P$ & $1.1 \times 10^{-7}$ & $4.2 \times 10^{-8}$ \\
\hline $\mathrm{SE}$ & $5.0 \times 10^{-5}$ & $5.1 \times 10^{-5}$ \\
\hline $\mathrm{X}_{\text {MAX }}$ (Arsenite)/ $\mathrm{X}_{\text {MAX }}$ (Arsenate) & 2.0 & 1.9 \\
\hline $\mathrm{K}_{\mathrm{L}}($ Arsenite $) / \mathrm{K}_{\mathrm{L}}$ (Arsenate) & 0.2 & 0.2 \\
\hline
\end{tabular}

${ }^{\mathbf{z}}$ Standard deviation.

arsenite and arsenate adsorption. However, when the $\mathrm{X}_{\mathrm{MAX}}$ and $\mathrm{K}_{\mathrm{L}}$ values for arsenite adsorption were compared with those for arsenate (Table 3), the extent of the effect of HA coating on these values for arsenite and arsenate adsorption was quite comparable. Due to the net negative charge on the surfaces after HA coverage at $\mathrm{pH} 6.5$ (Table 1), a higher electrostatic repulsion could have been expected to hamper arsenate anions, negatively charged at the experimental $\mathrm{pH}$, to approach the surfaces, whereas arsenite, mostly undissociated (and thus uncharged) at $\mathrm{pH} 6.5$, would be less affected by the negative electrostatic barrier. The virtually identical extent of the effect of HA coating on the maximum adsorption capacity and adsorption affinity constant values for the adsorption of arsenite and arsenate on the two adsorbents suggests that competition for the same reactive sites $\left(\mathrm{Fe}-\mathrm{OH}_{2}\right.$ and $\mathrm{OH})$ on the ferrihydrite-covered surface by the adsorbed organic molecules (Simeoni et al. 2003; Bauer and Blodau 2006), coupled with the steric hindrance of the large humic molecules to restrict the arsenite and arsenate to approach surfaces, rather than the electrostatic repulsion, could represent the main mechanisms in reducing arsenite and arsenate adsorption in the presence of the HA. The presence of a peat HA adsorbed on goethite reduced arsenite and arsenate adsorption, especially at $\mathrm{pH}$ unfavourable for the adsorption of each As species (Grafe et al. 2001), while the same HA did not affect arsenite and arsenate adsorption on ferrihydrite (Grafe et al. 2002). These authors concluded that different adsorption mechanisms for $\mathrm{HA}$ and for the two As species on ferrihydrite could occur. The observations in the present study, which differ from those reported by Grafe et al. (2002), could partly be due to the different characteristics of the HA used. However, it cannot be excluded that the reactivity of the ferrihydrite 
coating on the kaolinite surfaces could differ from that of discrete ferrihydrite particles of very small size, the surfaces of the kaolinite-ferrihydrite system apparently behaving more similarly to the smoother, larger particles of crystalline $\mathrm{Fe}$ oxides, such as goethite.

From the specific surface area determination, it appeared that only $58 \%$ of the specific surface area of the kaolinite-ferrihydrite system was available for $\mathrm{N}_{2}$ adsorption after partial HA coverage (Table 1); from the As adsorption data, the amounts of arsenite and arsenate adsorbed on $\mathrm{KGa} 2-\mathrm{Fh}-\mathrm{HA}$ were $81.1 \pm 4.7 \%$ and $84.8 \pm 0.6$, respectively, of those adsorbed on KGa2$\mathrm{Fh}$, without significant difference between the two As species. Part of the organic molecules could have been out-competed by arsenite and arsenate anions, due to their high affinity to the iron oxide (Grafe et al. 2001; Simeoni et al. 2003) and to their strong specific adsorption via inner-sphere complexes. Moreover, an interaction of the As species with the humic material via the protonated amino groups could occur as suggested by Saada et al. (2003), although this mechanism likely contributes at a minor extent compared with the direct adsorption of As on the oxide surfaces.

\section{Isothermal Titration Calorimetry}

Differences in the reaction mechanisms, possibly induced by the presence of the HA coating, could result in some changes in the thermodynamics of the reaction. The heat of adsorption of the arsenic species on the adsorbent systems, obtained with isothermal titration calorimetry, is shown in Fig. 3. The heterogeneity of the adsorption sites results in the decreasing of the heat released after each injection (Fig. 3), as observed by Miltenburg and Golterman (1998) for phosphate adsorption on Fe hydroxides. Decreases in the absolute values of adsorption enthalpy at increasing surface coverage have been reported for the adsorption of several anions on goethite (Machesky et al. 1989). The initial additions of arsenite or arsenate released higher heat and caused the progressive saturation of the more energetic sites; the successive reaction with the less energetic sites corresponded to progressively lower heat released (Fig. 3). The $\Delta \mathrm{H}$ values obtained by isothermal titration calorimetry for arsenite and arsenate adsorption on pure ferrihydrite, KGa2-Fh and KGa2-Fh-HA are reported in Table 4. Similar values were obtained for each adsorbent at two different concentrations of the titrant solution and the values in Table 4 were obtained as the average. The adsorption of oxyanions on mineral surfaces is a complex process, involving heterogeneous adsorbing sites (Hiemstra et al. 1989) and possibly the formation of different surface bonding. In fact, although arsenate (Waychunas et al. 1993; Sherman and Randall 2003) and arsenite (OnaNguema et al. 2005) are adsorbed on ferrihydrite with the prevalent formation of a binuclear, bidentate bonding, the coexistence of lower amounts of bidentate mononuclear (Manceau 1995) or monodentate

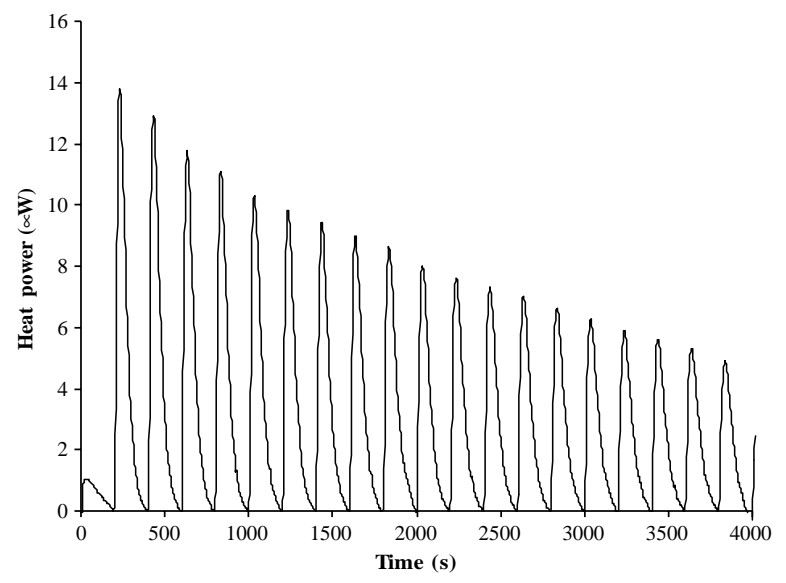

Fig. 3. Experimental titration curve for adsorption of arsenite on KGa2-Fh. Experimental conditions: $5 \mathrm{~g} \mathrm{~L}^{-1} \mathrm{KGa} 2-\mathrm{Fh} ; 4$ $\mathrm{mM}$ arsenite titrant solution; injection volume $10 \mu \mathrm{L}$; equilibration time between injections: 200 s; $\mathrm{pH}$ 6.5; temperature 298 K.

complexes (Waychunas et al. 1993; Ona-Nguema et al. 2005) have also been reported. The overall measured heat of adsorption is thus the result of the combination of different chemical processes that are not always easy to isolate. For this reason, only the overall $\Delta \mathrm{H}$ was obtained from the calorimetric measurements. The $\Delta \mathrm{H}$ values obtained under our experimental conditions were negative for both arsenite and arsenate adsorption on all adsorbents (Table 4), indicating an overall exothermic reaction in each reaction system. The $\Delta \mathrm{H}$ values for arsenate adsorption were always substantially more negative than those for arsenite adsorption. This indicates the formation of a stronger bonding of arsenate with the reactive sites compared with arsenite, in agreement with the much higher affinity constant values for the former than the latter (Table 3). The $\Delta \mathrm{H}$ values for the adsorption of arsenite and arsenate on pure ferrihydrite were higher compared with those for the $\mathrm{KGa} 2-\mathrm{Fh}$ system. Although ferrihydrite appeared to dominate the surface properties of the mixed system (Table 1), the $\Delta \mathrm{H}$ values (Table 4 ) indicate a discernible

Table 4. Enthalpy $(\Delta \mathrm{H})$ values of arsenite or arsenate adsorption on ferrihydrite (Fh), kaolinite-ferrihydrite (KGa2-Fh) and kaolinite-ferrihydrite-humate (KGa2-Fh-HA) systems determined by isothermal titration calorimetric measurements at $298 \mathrm{~K}$

\begin{tabular}{lcc}
\hline & \multicolumn{2}{c}{$\Delta \mathrm{H}\left(\mathrm{kJ} \mathrm{mol}^{-1}\right)$} \\
\cline { 2 - 3 } & \multicolumn{1}{c}{$\mathrm{As}(\mathrm{III})$} & $\mathrm{As}(\mathrm{V})$ \\
\hline Fh & $-32.9 \pm 2.0^{\mathbf{z}}$ & $-45.1 \pm 1.8$ \\
KGa2-Fh & $-24.4 \pm 2.7$ & $-39.9 \pm 3.3$ \\
KGa2-Fh-HA & $-22.3 \pm 1.4$ & $-36.4 \pm 1.5$ \\
\hline
\end{tabular}

${ }^{\mathrm{z}}$ Standard deviation. 
difference in the reactivity between discrete particles of ferrihydrite and ferrihydrite coating on kaolinite. The $\Delta \mathrm{H}$ values measured for arsenite and arsenate adsorption on the KGa2-Fh-HA system were slightly lower than those on the KGa2-Fh system; however, the differences were within the experimental error, showing that the presence of the HA on the ferrihydrite-coated kaolinite surface did not substantially affect the heat of adsorption.

The values reported in the literature for the heat of adsorption of oxyanions on oxide surfaces vary widely, and may be affected by the nature of the absorbent and absorbate, the composition of the solution and by all the factors affecting the adsorption reaction. Kabengi et al. (2006) measured exothermic heat of arsenate adsorption on amorphous $\mathrm{Al}$ hydroxides by flow calorimetry, ranging from -3.04 to $-66.3 \mathrm{~kJ} \mathrm{~mol}^{-1}$ for different experimental sets. Negative values of $\Delta \mathrm{H}$ were also reported for the adsorption of arsenite and arsenate on hematite (Singh et al. 1988, 1996), arsenate on goethite (Matis et al. 1999) and arsenite on activated alumina (Singh and Pant 2004), whereas Lakshmipathiraj et al. (2006) calculated a positive $\Delta \mathrm{H}$ value for arsenate adsorption on goethite. The energy of reaction for the same adsorbent/adsorbate system can actually vary according to the type of surface complex formed and the surface charge; Kwon and Kubicki (2004) reported that the calculated heat of adsorption of phosphate on iron oxides could be either endothermic or exothermic, ranging between +30 and $-61 \mathrm{~kJ} \mathrm{~mol}^{-1}$, according to the reaction conditions and kind of P-surface bonding formed. However, under our experimental conditions, the adsorption of arsenite and arsenate on the two mixed systems gave replicable results that did not appear to depend on the titrant concentration within a certain range [from 0.8 to $2 \mathrm{mM}$ for $\mathrm{As}(\mathrm{V})$ and from 1.3 to $4 \mathrm{mM}$ for As(III)] and that did not suggest substantial differences in the energetics of the adsorption by the two mixed systems (Table 4).

\section{Arsenite Adsorption Kinetics}

The kinetic studies focused on arsenite adsorption, since the reactivity of this arsenic form is less widely known than that of arsenate, in spite of its greater toxicity and mobility in many contaminated environments.

The arsenite adsorption in the first 5 min accounted for 72 and $60 \%$ of the arsenite adsorbed by $\mathrm{KGa} 2-\mathrm{Fh}$ and KGa2-Fh-HA, respectively, at the end of a $24 \mathrm{~h}$ equilibration period (Table 5). After $1 \mathrm{~h}, 92 \%$ of the adsorption at equilibrium was completed on the KGa2Fh system, whereas the presence of the HA coating slowed the adsorption process in the KGa2-Fh-HA system, to only $76 \%$ of the amount adsorbed at the equilibrium. However, after $4 \mathrm{~h}$, more than $90 \%$ of the equilibrium adsorption was completed in both the systems, which is in agreement with the findings of Raven et al. (1998). The ligand exchange reaction with the formation of the inner-sphere complex between arsenic and the surface of the iron oxide occurs within milliseconds (Grossl et al. 1997), whereas the diffusioncontrolled processes can be measured by batch experiments (Sparks 1989). The adsorption of arsenite (and arsenate) on Fe oxides is generally described as a fast reaction, followed by a slower process, possibly due to intra-particle diffusion or surface precipitation (Fuller et al. 1993; Raven et al. 1998); however, the quasiequilibrium reached within the first $24 \mathrm{~h}$ accounts for most of the adsorption process. O'Reilly et al. (2001) reported that over $93 \%$ of the arsenate adsorbed on goethite after 12 mo of interaction was adsorbed within the first $24 \mathrm{~h}$. The high percentage of the As adsorbed in the first measurement at the end of $5 \mathrm{~min}$ of the kinetic experiment suggested that most of the adsorbing sites on the ferrihydrite coating were quite readily accessible to arsenite, especially on the KGa2-Fh system, where As adsorption was apparently only partially controlled by diffusion processes.

The amount of arsenite adsorbed at different times of interaction was only slightly temperature dependent. The amount of arsenite adsorbed after $5 \mathrm{~min}, 1 \mathrm{~h}$ and 24 $\mathrm{h}$ was reported as an example (Table 6). It is interesting to notice that at the beginning of the kinetic study (from $5 \mathrm{~min}$ to $1 \mathrm{~h}$ of interaction) the amount of adsorbed arsenite increased with temperature with statistically significant differences at least between 288 and $318 \mathrm{~K}$. In the time interval between 2 and $12 \mathrm{~h}$, the amounts of adsorbed arsenite at the four different temperatures overlapped (data not shown). At the end of $24 \mathrm{~h}$ of interaction, however, the trend reversed, and the amount of arsenite adsorbed at $288 \mathrm{~K}$ was higher than that adsorbed at $318 \mathrm{~K}$. This apparently contradictory behaviour in the short time and at the equilibrium can be explained on the basis of the energy needed for the activation of the adsorption reaction and the net release of heat from the overall exothermic reaction (Table 4). The role played by each of these two factors is different at the beginning of the reaction compared with the equilibrium. The adsorption of the arsenite on the ferrihydrite surfaces $(\mathrm{Fh})$ via ligand exchange between the arsenite and the $\mathrm{Fe}-\mathrm{OH}_{2}$ and $\mathrm{Fe}-\mathrm{OH}$ groups can be summarized as follows:

$$
\text { Arsenite }+\mathrm{Fh}+\mathrm{h}_{1} \rightleftarrows \text { Fh-Arsenite }+\mathrm{h}_{2}
$$

where $h_{1}$ is the energy required for the activation of the adsorption reaction and $h_{2}$ is the energy released with the formation of the new ligand-surface bonding. At pre-equilibrium stages, the energetic inputs are necessary for the activation of the adsorption reaction driven by the excess of the concentration of the reactants in solution, whereas the reverse reaction, although favoured by the presence of heat, plays only a marginal role due to the low concentration of the product. The result is an enhancement of the adsorption reaction at higher temperature until the concentration of the products becomes high enough compared with the 
Table 5. Arsenite adsorption at different times, expressed as percentage of the As initially added and of the As adsorbed at equilibrium (24 h) by each adsorbent at $298 \mathrm{~K}$

\begin{tabular}{|c|c|c|c|c|c|c|}
\hline & \multicolumn{6}{|c|}{ As absorbed } \\
\hline & $0.083 \mathrm{~h}$ & $0.67 \mathrm{~h}$ & $1 \mathrm{~h}$ & $4 \mathrm{~h}$ & $12 \mathrm{~h}$ & $24 \mathrm{~h}$ \\
\hline & \multicolumn{6}{|c|}{$K G a 2-F h$} \\
\hline$\%$ added As & 56 & 64 & 71 & 75 & 77 & 77 \\
\hline \multirow[t]{2}{*}{$\%$ As adsorbed after $24 \mathrm{~h}$} & 72 & 83 & 92 & 96 & 99 & 100 \\
\hline & \multicolumn{6}{|c|}{$K G a 2-F h-H A$} \\
\hline$\%$ added As & 39 & 47 & 52 & 59 & 64 & 66 \\
\hline$\%$ As adsorbed after $24 \mathrm{~h}$ & 60 & 72 & 76 & 90 & 96 & 100 \\
\hline
\end{tabular}

concentration of the reactants with respect to the equilibrium concentrations. Then, as the equilibrium is approached, the rate of the reverse reaction becomes comparable with that of the forward reaction; due to the exothermic nature of the adsorption process, an increase in the temperature results in a smaller amount of the total arsenite adsorbed. Similarly, Machesky et al. (1989) found that the adsorbed amounts of several anions on goethite at $10^{\circ} \mathrm{C}$ were equal or slightly lower than those at $25^{\circ} \mathrm{C}$, although all the studied adsorption reactions were found to be exothermic, and this was attributed to the fact that the reaction at $10^{\circ} \mathrm{C}$ was the farthest from equilibrium.

From the statistical parameters reported in Fig. 4, it can be seen that the complete reaction period (0.083-24 h) was well described by the Elovich Eq. 1 (Chien and Clayton 1980):

$$
\mathrm{d} q / \mathrm{d} t=\alpha^{(-\beta q)}
$$

where $q$ is the amount of adsorbate adsorbed in the time $t$, and $\alpha$ and $\beta$ are empirical constants.

The equation was applied in the following simplified linear form (Chien and Clayton 1980):

$$
q=(1 / \beta) \ln (\alpha \beta)+(1 / \beta) \ln t
$$

The different effects of the temperature on arsenite adsorption at the beginning of the kinetic experiment and at near equilibrium are evident from the crossing of the Elovich plots of the adsorption kinetics at 288 and $318 \mathrm{~K}$ for both the KGa2-Fh and the KGa2-Fh-HA systems (Fig. 4a and b). The values calculated for $\beta$ and $\alpha$ at 288, 298, 308 and $318 \mathrm{~K}$ are reported in Table 7. As suggested by Chien and Clayton (1980), $\alpha$ can be regarded as the initial, rapid adsorption not governed by the exponential law, since $d q / d t \rightarrow \alpha$ as $q \rightarrow 0$; while $\beta$ may be regarded as a desorption constant (Gupta and Bhattacharyya 2006). In general, a decrease in the values of $\beta$ and/or an increase in the values of $\alpha$ should indicate an enhancement of the reaction rate (Chien and Clayton 1980). In the present case, both $\alpha$ and $\beta$ values increased with the temperature. This could possibly be related to the variation in the temperature dependence of adsorption with time, ranging from an enhancing effect at the beginning of the studied reaction period to an inhibiting effect at equilibrium. The enhancing effect of the temperature on the adsorption rate was, in fact, limited to the short term, as expressed by the increase of $\alpha$ values. The increasing values of $\beta$ indicated an overall slowing of the adsorption kinetics in the $0.083-24 \mathrm{~h}$ period with increasing temperature due to the increased influence of the desorption reaction as the equilibrium

Table 6. Amount of arsenite adsorbed as a function of reaction time and at different temperatures by kaolinite-ferrihydrite (KGa2-Fh) and kaolinite-

\begin{tabular}{|c|c|c|c|c|c|c|}
\hline \multicolumn{7}{|c|}{ Arsenic adsorbed $\left(\mu \mathrm{mol} \mathrm{g}^{-1}\right)$} \\
\hline \multirow[t]{2}{*}{ Reaction period } & \multicolumn{4}{|c|}{ Temperature (K) } & \multirow[b]{2}{*}{ SE } & \multirow[b]{2}{*}{$\operatorname{LSD}_{0.05}$} \\
\hline & 288 & 298 & 308 & 318 & & \\
\hline \multicolumn{7}{|c|}{$K G a 2-F h$} \\
\hline $0.083 \mathrm{~h}$ & 42.69 & 44.79 & 46.36 & 47.06 & 0.46 & 1.97 \\
\hline $1 \mathrm{~h}$ & 53.36 & 57.18 & 55.52 & 56.36 & 0.25 & 1.06 \\
\hline $24 \mathrm{~h}$ & 63.30 & 61.87 & 61.78 & 61.00 & 0.14 & 0.59 \\
\hline \multicolumn{7}{|c|}{ KGa2-Fh-HA } \\
\hline $0.083 \mathrm{~h}$ & 28.69 & 31.48 & 31.72 & 33.12 & 0.49 & 2.14 \\
\hline $1 \mathrm{~h}$ & 40.01 & 41.54 & 42.59 & 42.66 & 0.35 & 1.51 \\
\hline $24 \mathrm{~h}$ & 53.63 & 52.74 & 52.33 & 51.17 & 0.28 & 1.19 \\
\hline
\end{tabular}
ferrihydrite-humate (KGa2-Fh-HA) systems 


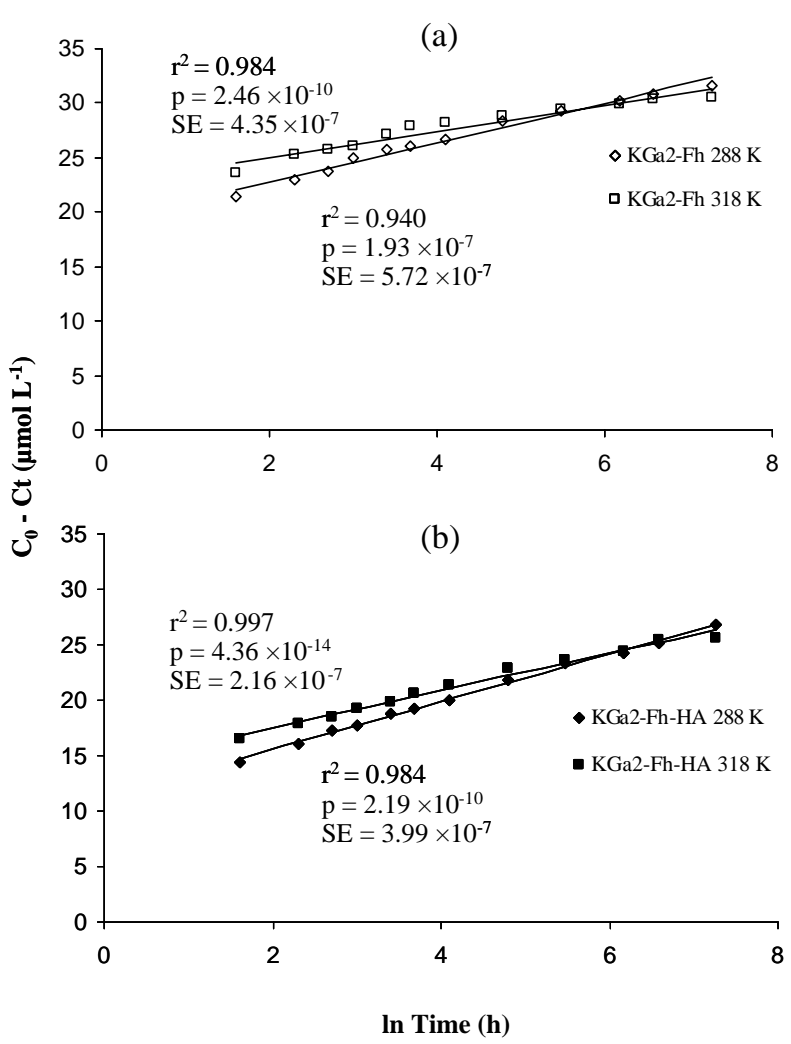

Fig. 4. Elovich plots of arsenite adsorption kinetics (0-24 h) on (a) KGa2-Fh and (b) KGa2-Fh-HA mixed systems at $288 \mathrm{~K}$ and $318 \mathrm{~K}$, where $\mathrm{C}_{0}$ and $\mathrm{C}_{\mathrm{t}}$ are the concentration of arsenite in solution at the beginning of the experiment and at different sampling times, respectively.

was approached, which is in agreement with the negative enthalpy values of both the reaction systems (Table 4). The values of $\alpha$ were 2 to 5 orders of magnitude higher for the KGa2-Fh system compared with the KGa2-FhHA system. This was attributed to the HA coating that partially blocked the adsorption sites and/or hampered arsenite reaching the adsorption sites. The slightly higher values of $\beta$ for the $\mathrm{KGa} 2-\mathrm{Fh}$ adsorbent compared with the KGa2-Fh-HA could be due to the fact that the adsorption reaction on the $\mathrm{KGa} 2-\mathrm{Fh}$ system was already closer to the equilibrium compared with that on the KGa2-Fh-HA system (Table 5), and thus more affected by the reverse reaction.

However, although the Elovich equation was found to adequately describe anion adsorption on soils and soil minerals (Chien and Clayton 1980; Elkhatib et al. 1984; Zhao and Stanforth 2001; Zhang and Stanforth 2005), the parameters provided by the empirical equation are not physicochemically well defined (Aharoni et al. 1991; Sparks 2003).

On the basis of the steepness of the kinetic curves, the adsorption kinetics of arsenite on the two mixed systems could be divided into a fast reaction step $(0.083-1 \mathrm{~h})$, followed by a slower reaction (1-24 h) (data not shown). This multi-phasic behaviour of arsenate adsorption has been observed in several studies on pure $\mathrm{Al}$ and $\mathrm{Fe}$ oxides (Fuller et al. 1993; Raven et al. 1998; O'Reilly et al. 2001; Arai and Sparks 2002) and soils (Livesey and Huang 1981; Zhang and Selim 2005). The multi-step rate processes have also been reported for the adsorption kinetics of different anions such as phosphate and selenite (Liu and Huang 2000; Saha et al. 2004) and cations, such as $\mathrm{Pb}$ and $\mathrm{Cd}$ (Liu and Huang 2003; Yu et al. 2006) and is generally attributed to the heterogeneity at the adsorption sites with different binding strength and different accessibility to the interior pores.

There is no consistent relationship between the equation giving the best fitting and the nature of the adsorption process involved, and dissimilar processes can be fitted by the same equation or, vice versa, similar processes can be fitted by different equation (Aharoni et al. 1991; Galwey 2003). Nevertheless, the parameters of the chosen model can provide some meaningful tools to compare the rates of the adsorption processes on

Table 7. Values of Elovich $\beta$ and $\alpha$ for arsenite adsorption in kaolinite-ferrihydrite (KGa2-Fh) and kaolinite-ferrihydrite-humate (KGa2-Fh-HA) systems in the $24 \mathrm{~h}$ reaction period

\begin{tabular}{|c|c|c|c|c|c|c|}
\hline & \multicolumn{4}{|c|}{ Temperature (K) } & \multirow[b]{2}{*}{$\mathrm{SE}$} & \multirow[b]{2}{*}{$\mathrm{LSD}_{0.05}$} \\
\hline & 288 & 298 & 308 & 318 & & \\
\hline \multicolumn{7}{|c|}{ Elovich $\beta$} \\
\hline $\mathrm{KGa} 2-\mathrm{Fh}$ & $5.5 \times 10^{5}$ & $6.6 \times 10^{5}$ & $7.6 \times 10^{5}$ & $8.3 \times 10^{5}$ & $1.9 \times 10^{4}$ & $4.7 \times 10^{4}$ \\
\hline KGa2-Fh-HA & $4.7 \times 10^{5}$ & $5.2 \times 10^{5}$ & $5.1 \times 10^{5}$ & $5.9 \times 10^{5}$ & $3.2 \times 10^{3}$ & $7.5 \times 10^{3}$ \\
\hline SE & $6.8 \times 10^{3}$ & $7.5 \times 10^{3}$ & $2.2 \times 10^{4}$ & $9.7 \times 10^{3}$ & & \\
\hline \multirow{2}{*}{$\operatorname{LSD}_{0.05}^{\mathbf{Z}}$} & $2.2 \times 10^{4}$ & $2.4 \times 10^{4}$ & $6.8 \times 10^{4}$ & $3.1 \times 10^{4}$ & & \\
\hline & & & Elovich $\alpha$ & & & \\
\hline KGa2-Fh & $4.1 \times 10^{0}$ & $1.0 \times 10^{2}$ & $1.7 \times 10^{3}$ & $1.1 \times 10^{4}$ & $2.1 \times 10^{3}$ & $5.1 \times 10^{3}$ \\
\hline KGa2-Fh-HA & $2.5 \times 10^{-2}$ & $1.0 \times 10^{-1}$ & $1.6 \times 10^{-1}$ & $4.6 \times 10^{-1}$ & $1.2 \times 10^{-2}$ & $2.9 \times 10^{-2}$ \\
\hline SE & $4.2 \times 10^{-1}$ & $2.1 \times 10^{1}$ & $1.2 \times 10^{3}$ & $3.1 \times 10^{3}$ & & \\
\hline $\mathrm{LSD}_{0.05}$ & $1.3 \times 10^{0}$ & $6.7 \times 10^{1}$ & $3.7 \times 10^{3}$ & $9.9 \times 10^{3}$ & & \\
\hline
\end{tabular}

${ }^{\mathbf{z}}$ Least significant difference calculated at $95 \%$ confidence level. 
different adsorbents (Liu and Huang 2000; Saha et al. 2004) at least under the same experimental conditions. Comparing the fittings of the zero-, first- and secondorder rate equations to the kinetic data, the secondorder rate equation was found to better describe the adsorption data for both the $0.083-1 \mathrm{~h}$ and the $1-24 \mathrm{~h}$ steps of the adsorption kinetics at 288 and $318 \mathrm{~K}$ [Zeroorder: $0.907<r^{2}<0.668 ; 3.2 \times 10^{-2}<P<1.2 \times 10^{-3}$; $1.1 \times 10^{-6}<\mathrm{SE}<3.9 \times 10^{-7}$; first-order: $0.923<r^{2}<$ $0.691 ; 2.4 \times 10^{-2}<P<3.7 \times 10^{-4} ; 1.2 \times 10^{-6}<\mathrm{SE}<$ $3.4 \times 10^{-7}$; second-order: $0.963<r^{2}<0.711 ; 1.7 \times$ $\left.10^{-2}<P<8.9 \times 10^{-5} ; \quad 1.4 \times 10^{-6}<\mathrm{SE}<3.2 \times 10^{-7}\right]$. Therefore, the second-order rate equation was chosen to fit the kinetic data as illustrated in Fig. 5. Similarly, phosphate adsorption on Fe oxides and selenite adsorption on hydroxy-Al-montmorillonite complexes were found to be properly described by the second-order rate equation (Liu and Huang 2000; Saha et al. 2004).

The effect of temperature on the rate constant values of arsenite adsorption (Table 8) is in accord with the trend observed for the adsorbed amount of arsenite described in Table 6. Although higher rate constants were obtained for both the systems at the higher temperature in the short $(0.083-1 \mathrm{~h})$ reaction time, in the longer period (1-24 h) the higher rate constant was obtained at the lower temperature, indicating the inhibiting effect of temperature on arsenite adsorption equilibrium in the present adsorbent/adsorbate systems. Besides the significant lowering of the amount of arsenite adsorbed at equilibrium in the presence of the HA (Table 3), the rate constants of arsenite adsorption for the $\mathrm{KGa} 2-\mathrm{Fh}$ system were always significantly higher than those calculated for the KGa2-Fh-HA system (Table 8), indicating a general hindering effect of the humic cover on the rate of arsenite adsorption. Although the negative charge on the KGa2-Fh-HA system was increased by the HA coating as shown by the PZC and $\zeta$ potential values (Table 1), arsenite exists as uncharged molecules at the $\mathrm{pH}$ of the reaction systems. Therefore, the charge effect was apparently relatively minor during adsorption. The hindering effect of the HA coverage was ascribed to the blocking of the reaction sites $\left(\mathrm{Fe}-\mathrm{OH}_{2}\right.$ and $\left.\mathrm{Fe}-\mathrm{OH}\right)$ as well as to the steric hindrance of the big humic molecules, restricting the accessibility of arsenite to the adsorbing sites, especially those inside the small pores, as can be deduced from the decreased accessibility of the pores to $\mathrm{N}_{2}$ adsorption (Table 1).

From the values of the rate constants obtained at different temperatures, the Arrhenius heat of activation values were calculated according to the following equation (Daniels et al. 1962):

$$
\log \frac{k_{\mathrm{T} 2}}{k_{\mathrm{T} 1}}=\frac{E_{a}}{2.303 R} \frac{\left(T_{2}-T_{1}\right)}{T_{2} T_{1}}
$$

where $\mathrm{k}_{\mathrm{T} 1}$ and $\mathrm{k}_{\mathrm{T} 2}$ are the rate constants calculated at the absolute temperature $T_{1}$ and $T_{2}$ respectively; $E_{a}$ is the Arrhenius heat of activation, and $\mathrm{R}$ is the universal molal gas constant.

The pre-exponential factor, expressing the collision frequency, was then calculated from the Arrhenius equation (Moore and Pearson 1981):

$$
\mathrm{k}=\mathrm{A} \mathrm{e}^{-\mathrm{Ea} / \mathrm{RT}}
$$

where $\mathrm{k}$ is the rate constant, $\mathrm{A}$ is the pre-exponential factor, $E_{a}$ is the Arrhenius heat of activation, and $R$ is the universal molal gas constant.

In this study, the adsorption data obtained at 288 and $318 \mathrm{~K}$ were used in the calculation of the kinetic data. This temperature range is environmentally relevant. Furthermore, at an air temperature of $25^{\circ} \mathrm{C}(298 \mathrm{~K})$ the corresponding temperature of the exposed soil surface to sunlight is $45^{\circ} \mathrm{C}$ (318 K) (Jury et al. 1991).

The values of the activation energy and pre-exponential factor for the fast reaction $(0.083-1 \mathrm{~h})$ are presented in Table 9. At the end of this reaction period, however, 92 and $76 \%$ of the arsenite adsorption was completed in the KGa2-Fh and KGa2-Fh-HA systems, respectively (Table 5). The $\mathrm{E}_{\mathrm{a}}$ values for both the adsorption systems were much lower than $42 \mathrm{~kJ} \mathrm{~mol}^{-1}$ (Table 9), indicating that, within the examined interval of time, the diffusion was the rate-limiting process in arsenite adsorption in the two mixed systems (Sparks 1999). The pre-exponential factor values, which give an indication of the accessibility of the adsorbate ions to the surfaces and the frequency of collision of adsorbate ions with the adsorbent surface (Liu and Huang 2000; Yu et al. 2006), were lower when the HA coating was present, indicating the reduction of the reaction sites and/or the hindering effect of the humic molecules toward arsenite approaching the surfaces.

\section{CONCLUSIONS}

The formation of complex mineral and organo-mineral colloids plays a significant role in influencing environmental processes in the ecosystem. However, to date, the reactivity of complex adsorbents, representative of natural soil colloids has received scant attention. The results of the present work show that the formation of the humate-ferrihydrite-kaolinite complex system can affect the reactivity of ferrihydrite toward arsenite and arsenate, causing a decrease in the adsorption maximum as well as in the affinity of the adsorbent surfaces toward both the adsorbates. The adsorption of both the negatively charged arsenate and the mainly undissociated, uncharged arsenous acid was similarly affected by the humic coverage. This suggests that, in the present system, the electrostatic repulsion could play a secondary role compared with the occupancy of part of the adsorbing sites by humate and possibly to the steric hindrance of the large humic molecules. The $\Delta \mathrm{H}$ values 


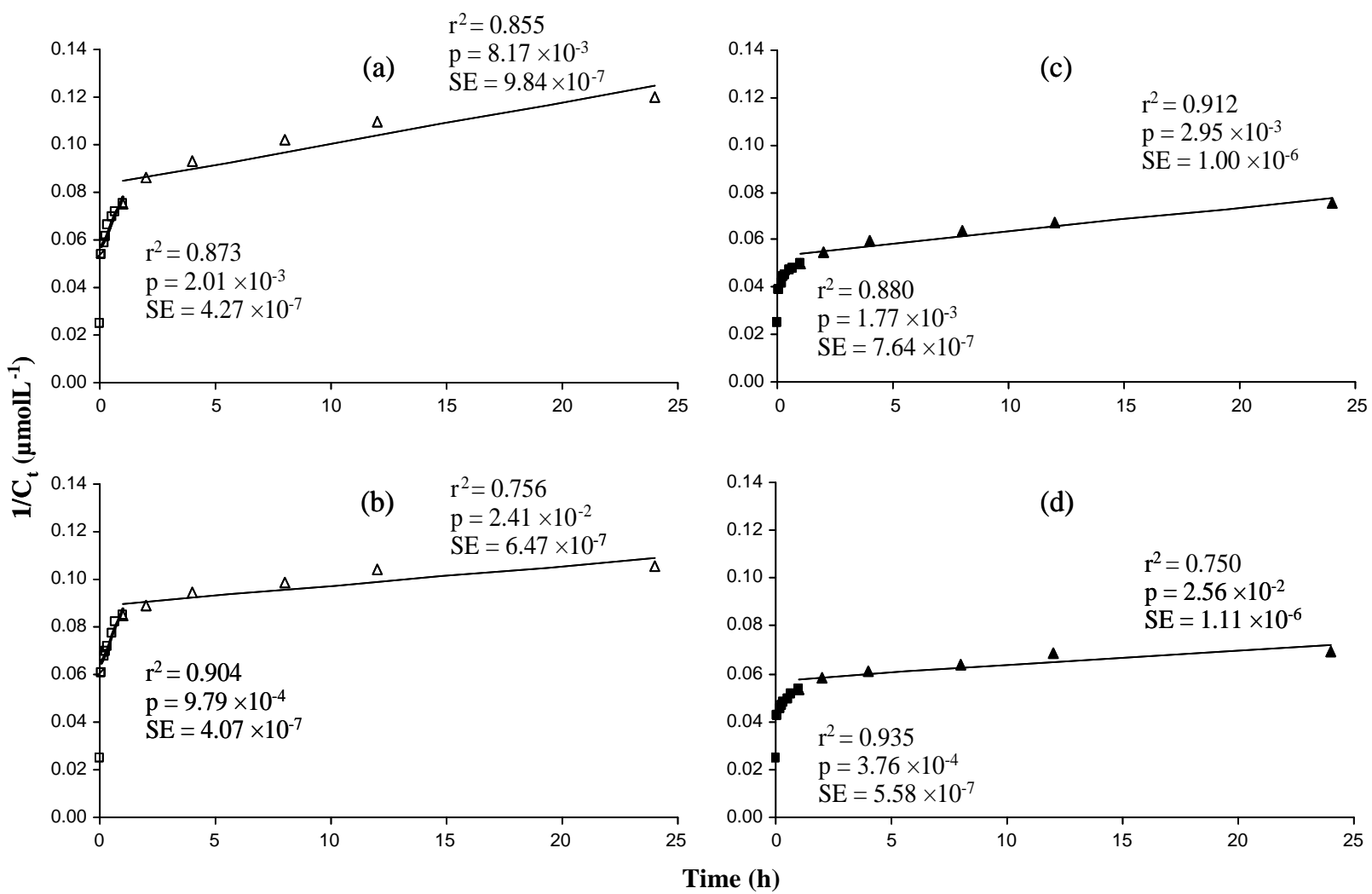

Fig. 5. Second-order plots of the kinetics of arsenite adsorption on: (a) KGa2-Fh at $288 \mathrm{~K}$; (b) KGa2-Fh at $318 \mathrm{~K}$; (c) KGa2-Fh-HA at $288 \mathrm{~K}$; and (d) $\mathrm{KGa}$-Fh-HA at $318 \mathrm{~K} . \mathrm{C}_{\mathrm{t}}$ is the concentration of arsenite in solution at different sampling times.

of arsenite and arsenate adsorption indicate that both the binding of arsenate and arsenite to the surfaces of ferrihydrite-kaolinite and humate-ferrihydrite-kaolinite systems were exothermic. There were only small differences in the $\Delta \mathrm{H}$ values between the two systems, suggesting that humic coating did not cause major changes in the thermodynamics of the adsorption reaction. Similarly, the calculated heat of activation did not show major differences; nevertheless the rate of

Table 8. Second-order rate constants $k$ of arsenite adsorption on the kaolinite-ferrihydrite (KGa2-Fh) and kaolinite-ferrihydrite-humate (KGa2-Fh-HA) systems

\begin{tabular}{lcccc}
\hline & KGa2-Fh & KGa2-Fh-HA & SE & LSD $_{0.05}^{\mathbf{z}}$ \\
\hline \multicolumn{5}{c}{$0.083-1 h k\left(M^{-1} h^{-1}\right)$} \\
$288 \mathrm{~K}$ & $2.24 \times 10^{4}$ & $1.09 \times 10^{4}$ & $3.73 \times 10^{2}$ & $9.14 \times 10^{2}$ \\
$318 \mathrm{~K}$ & $2.50 \times 10^{4}$ & $1.14 \times 10^{4}$ & $3.87 \times 10^{2}$ & $9.48 \times 10^{2}$ \\
SE & $5.32 \times 10^{2}$ & $2.35 \times 10^{2}$ & & \\
LSD $_{0.05}$ & $1.30 \times 10^{3}$ & $5.76 \times 10^{2}$ & \\
& & $1-24 h k\left(M^{-1} h^{-1}\right)$ & \\
$288 \mathrm{~K}$ & $1.46 \times 10^{3}$ & $8.93 \times 10^{2}$ & $2.91 \times 10^{1}$ & $7.14 \times 10^{1}$ \\
$318 \mathrm{~K}$ & $6.77 \times 10^{2}$ & $4.79 \times 10^{2}$ & $2.41 \times 10^{1}$ & $5.90 \times 10^{1}$ \\
SE $_{\text {LSD }}$ & $1.48 \times 10^{1}$ & $3.85 \times 10^{1}$ & & \\
& $3.62 \times 10^{1}$ & $9.42 \times 10^{1}$ & &
\end{tabular}

${ }^{\mathrm{z}}$ Least significant difference calculated at $95 \%$ confidence level. arsenite adsorption was substantially slowed down by the presence of the organic molecules due to a decreased collision frequency. This is attributable to the blocking effect of the reaction sites and/or steric hindrance by the organic ligands.

\section{ACKNOWLEDGEMENTS}

This study was supported by Discovery Grant 23832008 of the Natural Sciences and Engineering Research

Table 9. Activation energy $\left(E_{a}\right)$ and pre-exponential factor (A) for arsenite adsorption on the kaolinite-ferrihydrite (KGa2-Fh) and kaolinite-ferrihydrite-humate (KGa2-Fh-HA) systems in the 0.083-1 h time interval

\begin{tabular}{lc}
\hline & $\mathrm{E}_{\mathrm{a}}\left(\mathrm{kJ} \mathrm{mol}^{-1}\right)$ \\
\hline KGa2-Fh & 2.86 \\
KGa2-Fh-HA & 0.53 \\
$\mathrm{SE}$ & 0.52 \\
$\mathrm{LSD}$ & 1.27 \\
& $\mathrm{~A}\left(\mathrm{M}^{-1} \mathrm{~h}^{-1}\right)$ \\
$\mathrm{KGa} 2-\mathrm{Fh}$ & $1.07 \times 10^{4}$ \\
$\mathrm{KGa} 2-\mathrm{Fh}-\mathrm{HA}$ & $7.67 \times 10^{3}$ \\
$\mathrm{SE}$ & $6.36 \times 10^{3}$ \\
$\mathrm{LSD}_{0.05}$ & $1.56 \times 10^{4}$ \\
\hline
\end{tabular}

${ }^{\mathrm{z}}$ Least significant difference calculated at $95 \%$ confidence level. 
Council of Canada, and the Italian Ministry of University and Research (MIUR), PRIN Project. The Isothermal Titration Calorimetry experiments were performed at the Saskatchewan Structural Sciences Center. Dr. J. Maley is gratefully acknowledged for his help in obtaining and interpreting the calorimetric results.

Aharoni, C., Sparks, D. L. Levinson, S. and Ravina, I. 1991. Kinetics of soil chemical reactions: relationship between empirical equations and diffusion models. Soil Sci. Soc. Am. J. 55: $1307-1312$.

Andreux, F. 1996. Humus in world soils. Pages 45-100 in A. Piccolo, ed. Humic substances in terrestrial ecosystems. Elsevier, Amsterdam, the Netherlands.

Arai, Y., Elzinga, E. J. and Sparks, D. L. 2001. X-ray absorption spectroscopic investigation of arsenite and arsenate adsorption at the aluminum oxide-water interface. J. Colloid Interface Sci. 235: 80-88.

Arai, Y. and Sparks, D. L. 2002. Residence time effect on arsenate surface speciation at the aluminum oxide-water interface. Soil Sci. 167: 303-314.

Arias, M., Barral, M. T. and Diaz-Fierro, F. 1995. Effects of iron and aluminium oxides on the colloidal and surface properties of kaolin. Clays Clay Miner. 43: 406-416.

Barrow, N. J. 1974. On the displacement of adsorbed anions from soil: 2. Displacement of phosphate by arsenate. Soil Sci. 117: 28-33.

Bauer, M. and Blodau, C. 2006. Mobilization of arsenic by dissolved organic matter from iron oxides, soils and sediments. Sci. Total Environ. 345: 179-190.

Celi, L., De Luca, G. and Barberis, E. 2003. Effects of interaction of organic and inorganic $\mathrm{P}$ with ferrihydrite and kaolinite-iron oxide systems on iron release. Soil Sci. 168: 479 488.

Celi, L., Schnitzer, M. and Nègre, M. 1997. Analysis of carboxyl groups in soil humic acids by a wet chemical method, fourier-transform infrared spectrophotometry, and solutionstate carbon-13 nuclear magnetic resonance. A comparative study. Soil Sci. 162: 189-197.

Celis, R., Cornejo, J. and Hermosin, M. C. 1998. Textural properties of synthetic clay-ferrihydrite associations. Clay Miner. 33: 395-407.

Chen, Y., Senesi, N. and Schnitzer, M. 1977. Information provided on humic substances by $\mathrm{E}_{4} / \mathrm{E}_{6}$ ratios. Soil Sci. Soc. Am. J. 41: 352-358.

Chien, S. H. and Clayton, W. R. 1980. Application of Elovich equation to the kinetics of phosphate release and sorption in soils. Soil Sci. Soc. Am. J. 61: 772-783.

Cornell, R. M. and Schwertmann, U. 1996. The iron oxides. VCH - Verlagsgesellschaft, Weinheim, New York, NY.

Cornu, S., Breeze, D., Saada, A. and Baranger, P. 2003. The influence of $\mathrm{pH}$, electrolyte type, and surface coating on arsenic(V) adsorption onto kaolinites. Soil Sci. Soc. Am. J. 67: 1127-1132.

Daniels, F., Williams, J. W., Bender, P., Alberty, R. A. and Cornwell, C. D. 1962. Experimental physical chemistry. 6th ed. McGraw-Hill Book Company Inc., New York, NY.

De Brouwere, K., Smolders, E. and Merckx, R. 2004. Soil properties affecting solid-liquid distribution of $\mathrm{As}(\mathrm{V})$ in soils. Eur. J. Soil Sci. 55: 165-173. de Jonge, H., de Jonge, L.W. and Mittelmeijer-Hazeleger, M. C. 2000. The microporous structure of organic and mineral soil materials. Soil Sci. 165: 99-108.

Dixit, S. and Hering, J. G. 2003. Comparison of $\operatorname{arsenic(V)}$ and arsenic(III) sorption onto iron oxide minerals: Implications for arsenic mobility. Environ Sci. Technol. 37: 4182-4189.

Elkhatib, E. A., Bennett, O. L. and Wright, R. J. 1984. Kinetics of arsenite adsorption in soils. Soil Sci. Soc. Am. J. 48: $758-762$.

Fuller, C. C., Davis, J. A. and Waychunas, G. A. 1993. Surface chemistry of ferrihydrite: Part 2. Kinetics of arsenate adsorption and copricipitation. Geochim. Cosmochim. Acta. 57: 2271-2282.

Galwey, A. K. 2003. Eradicating erroneous Arrhenius arithmetic. Thermochim. Acta 399: 1-29.

Goldberg S. and Johnston, C. T. 2001. Mechanisms of arsenic adsorption on amorphous oxides evaluated using macroscopic measurements, vibrational spectroscopy and surface complexation modeling. J. Colloid Interface Sci. 234: 204-216.

Grafe, M., Eick, M. J. and Grossl, P. R. 2001. Adsorption of arsenate (V) and arsenite (III) on goethite in the presence and absence of dissolved organic carbon. Soil Sci. Soc. Am. J. 65: 1680-1687.

Grafe, M., Eick, M. J., Grossl, P. R. and Saunders, A. M. 2002. Adsorption of arsenate and arsenite on ferrihydrite in the presence and absence of dissolved organic carbon. J. Environ. Qual. 31: 1115-1123.

Grossl, P. R., Eich, M. J., Sparks, D. L., Goldberg, S. and Ainsworth, C. C. 1997. Arsenate and chromate retention mechanisms on goethite. 2. Kinetic evaluation using a pressure-jump relaxation technique. Environ. Sci. Technol. 31: $321-326$.

Gupta, S. S. and Bhattacharyya, K. G. 2006. Adsorption of Ni (II) on clays. J. Colloid Interface Sci. 295: 21-32.

Hiemstra, T., van Riemdijk, W. H. and Bolt, H. 1989. Multisite proton adsorption modeling at the solid/solution interface of (hydr)oxides: a new approach. I. Model description and evaluation of intrinsic reaction constants. J. Colloid Interface Sci. 133: 91-104.

Huang, P. M. and Fujii, R. 1996. Selenium and arsenic. Pages 793-831 in D. L. Sparks, ed. Methods of soil analysis. Part 3. Chemical methods. SSSA Book Series No. 5. SSSA, ASA, Madison, WI.

Jain, A., Raven, K. P. and Loeppert, R. H. 1999. Arsenite and arsenate adsorption on ferrihydrite: surface charge reduction and net $-\mathrm{OH}^{-}$release stoichiometry. Environ. Sci. Technol. 33: 1179-1184.

Jury, W. A., Gardner, W. R. and Gardner, W. H. 1991. Soil physics. 5th ed. John Wiley and Sons, Inc., New York, NY.

Kabengi, N. J., Daroub, S. H. and Rhue, R. D. 2006. Energetics of arsenate sorption on amorphous aluminum hydroxides studied using flow adsorption calorimetry. J. Colloid Interface Sci. 297: 86-94.

Kaiser, K. and Guggenberger, G. 2003. Mineral surfaces and soil organic matter. Eur. J. Soil Sci. 54: 219-236.

Kalbitz, K. and Wennrich, R. 1998. Mobilization of heavy metals and arsenic in polluted wetland soils and its dependence on dissolved organic matter. Sci. Total Environ. 209: 27-39.

Kretzschmar, R. and Sticher, H. 1997. Transport of humiccoated iron oxide colloids in a sandy soil: influence of $\mathrm{Ca}^{2+}$ and trace metals. Environ. Sci. Technol. 31: 3497-3504.

Kwon, K. D. and Kubicki, J. D. 2004. Molecular orbital theory study on surface complex structures of phosphates to iron 
oxides: calculation of vibrational frequencies and adsorption energies. Langmuir 20: 9249-9254

Lakshmipathiraj, P., Narasimhan, B. R. V., Prabhakar, S. and Bhaskar Raju, G. 2006. Adsorption of arsenate on synthetic goethite from aqueous solutions. J. Hazard. Mater. B 136: 281-287.

Lide, D. R. 2007. Handbook of chemistry and physics. 87th ed. 2006-07. CRC Press, Boca Raton, FL.

Liu, C. and Huang, P. M. 2000. Kinetics of phosphate adsorption on iron oxides formed under the influence of citrate. Can. J. Soil Sci. 80:445-454.

Liu, C. and Huang, P. M. 2003. Kinetics of lead adsorption by iron oxides formed under the influence of citrate. Geochim. Cosmochim. Acta 67: 1045-1054.

Livesey, N. T. and Huang, P. M. 1981. Adsorption of arsenate by soils and its relation to selected chemical properties and anions. Soil Sci. 131: 88-94.

Machesky, M. L., Blschoff, B. L. and Anderson, M. A. 1989. Calorimetric investigation of anion adsorption onto goethite. Environ. Sci. Technol. 23: 580-587.

Manceau, A. 1995. The mechanism of anion adsorption on iron oxides: Evidence for the bonding of arsenate tetrahedra on free $\mathrm{Fe}(\mathrm{O}, \mathrm{OH}) 6$ edges. Geochim. Cosmochim. Acta 59: 3647-3653.

Mandal, B. K and Suzuki, K. T. 2002. Arsenic round the world: a review. Talanta 58: 201-235.

Martin, M. 2003. Modificazione delle proprietà di superficie e dissoluzione della ferridrite pura o associata a caolinite ad opera di differenti frazioni della sostanza organica del suolo. $\mathrm{PhD}$ thesis. University of Turin, Turin, Italy.

Martin, M., Violante, A. and Barberis, E. 2007. Fate of arsenite and arsenate in flooded and not flooded soils of southwest Bangladesh irrigated with arsenic contaminated water. J. Environ. Sci. Health A42: 1775-1783.

Masschelein, P. H., Delaune, R. D. and Patrick Jr., W. H. 1991. Effect of redox potential and $\mathrm{pH}$ on arsenic speciation and solubility in a contaminated soil. J. Environ. Qual. 25: 1414-1419.

Matis, K. A., Zouboulis, A. I., Zamboulis, D. and Valtadorou, A. V. 1999. Sorption of As(V) by goethite particles and study of their flocculation. Water Air Soil Pollut. 111: 297-316.

Miltenburg, J. C. and Golterman, H. L. 1998. The energy of the adsorption of o-phosphate onto ferric hydroxide. Hydrobiologia 364: 93-97.

Moore, J. W. and Pearson, R. G. 1981. Kinetics and mechanisms. 3rd ed. John Wiley and Sons Inc., New York, NY.

Ona-Nguema, G., Morin, G., Juillot, F., Calas, G. and Brown Jr., G. E. 2005. EXAFS analysis of arsenite adsorption onto two-line ferrihydrite, hematite, goethite, and lepidocrocite. Environ. Sci. Technol. 39: 9147-9155.

O'Reilly, S. E., Strawn, D. G. and Sparks, D. L. 2001. Residence time effect on arsenate adsorption/desorption mechanisms on goethite. Soil Sci. Soc. Am. J. 65: 67-77.

Oscarson, D. W., Huang, P. M. and Liaw, W. K. 1981. The role of manganese in the oxidation of arsenate by freshwater lake sediments. Clays Clay Miner. 28: 219-225.

Parfitt, R. L., Fraser, A. R. and Farmer,V. C. 1977. Adsorption on hydrous oxides. III. Fulvic acid and humic acid on goethite, gibbsite and imogolite. J. Soil Sci. 28: 289-296.

Pennell, K. D., Boyd, S. A. and Abriola, L. M. 1995. Surface area of soil organic matter reexamined. Soil Sci. Soc. Am. J. 59: 1012-1018.
Pierce, M. L. and Moore, C. B. 1982. Adsorption of arsenite and arsenate on amorphous iron hydroxide. Water Res. 16: 1247-1253.

Raven, K., Jain, A. and Loeppert, R. H. 1998. Arsenite and arsenate adsorption on ferrihydrite: kinetics, equilibrium, and adsorption envelopes. Environ. Sci. Technol. 32: 344-349.

Saada, A., Breeze, D., Crouzet, C., Cornu, S. and Baranger, P. 2003. Adsorption of arsenic $(\mathrm{V})$ on kaolinite and on kaolinitehumic acid complexes. Role of humic acid nitrogen groups. Chemosphere 51: 757-763.

Sadiq, M. 1997. Arsenic chemistry in soils: an overview of thermodynamic predictions and field observations. Water Air Soil Pollut. 93: 117-136.

Saha, U. K., Liu, C., Kozak, L. M. and Huang, P. M. 2004. Kinetics of selenite adsorption on hydroxyaluminum- and hydroxyaluminumsilicate-montmorillonite complexes. Soil Sci. Soc. Am. J. 68: 1197-1209.

Schwertmann, U. and Cornell, R. M. 1991. Iron oxides in the laboratory, preparation and characterization. $\mathrm{VCH}$, Weinheim, Germany.

Schnitzer, M. 1978. Humic substances: chemistry and reactions. Pages 1-58 in M. Schnitzer and S. U. Khan, eds. Soil organic matter. Elsevier Scientific Publishing Company, Amsterdam, the Netherlands

Schnitzer, M. 1995. Organic-inorganic interactions in soils and their effects on soil quality. Pages 3-19 in P. M. Huang, J. Berthelin, J.-M. Bollag, W. B. MsGill, and A. L. Page, eds. Environmental impact of soil component interactions. Natural and anthropogenic organics.. Lewis Publishers, Boca Raton, FL.

Schnitzer, M. and Gupta, E. V. C. 1965. Determination of acidity in soil organic matter. Soil Sci. Soc. Am. Proc. 29: 274-277.

Shao, Z. C. and Wang, W. J. 1991. Relationship between iron oxides and surface charge characteristics in soils. Pedosphere 1: 29-39.

Sherman, D. M. and Randall, S. R. 2003. Surface complexation of arsenic(V) to iron(III) (hydr)oxides: structural mechanism from ab initio molecular geometries and EXAFS spectroscopy. Geochim. Cosmochim. Acta 67: 4223-4230.

Simeoni, M. A., Batts, B. D. and Mc Rae, C. 2003. Effect of groundwater fulvic acid on the adsorption of arsenate by ferrihydrite and gibbsite. Appl. Geochem. 18: 1507-1515.

Singh, D. B., Prasad, G., Rupainwar, D. C. and Singh, V. N. 1988. As(III) removal from aqueous solution by adsorption. Water Air Soil Pollut. 42: 373-386.

Singh, D. B., Prasad, G. and Rupainwar, D. C. 1996. Adsorption technique for the treatment of $\mathrm{As}(\mathrm{V})$-rich effluents. Colloid Surface A 111: 49-56.

Singh, T. S. and Pant, K. K. 2004. Equilibrium, kinetics and thermodynamic studies for adsorption of As(III) on activated alumina. Sep. Purif. Technol. 36: 139-147.

Smedley, P. L. and Kinniburgh, D. G. 2002. A review of the source, behaviour and distribution of arsenic in natural waters. Appl. Geochem. 17: 517-568.

Smith, E., Naidu, R. and Alston, A. M. 1998. Arsenic in the soil environment: a review. Adv. Agron. 64: 149-195.

Sparks, D. L. 1989. Kinetics of soil chemical processes. Academic Press, New York, NY.

Sparks, D. L. 1999. Kinetics of sorption/release reactions at the soil mineral/water interface. Pages 135-191 in D. L. 
Sparks, ed. Soil physical chemistry. 2nd ed. CRC Press, Boca Raton, FL.

Sparks, D. L. 2003. Environmental soil chemistry. 2nd ed. Academic Press, New York, NY.

Styblo, M., Del Razo, L. M., Vega, L., Germolec, D. R., Le Cluyse, E. L., Hamilton, G. A., Reed, W., Wang, C., Cullen, W. R. and Thomas, D. J. 2000. Comparative toxicity of trivalent and pentavalent inorganic and methylated arsenicals in rat and human cells. Arch. Toxicol. 74: 289-299.

Sun, X. and Doner, H. E. 1996. An investigation of arsenate and arsenite bonding structures on goethite by FTIR. Soil Sci. 161: 865-872.

Swift, R. S. 1996. Organic matter characterization. Pages 1011-1070 in D. L. Sparks, ed. Methods of soil analysis. Part 3. Chemical methods. SSSA Book Series No.5. SSSA and ASA, Madison, WI.

Tan, K. H. 2003. Humic matter in soil and the environment. Principles and controversies. Marcel Dekker Inc., New York, NY.
Waychunas, G. A., Rea, B. A., Fuller, C. C. and Davis, J. A. 1993. Surface chemistry of ferrihydrite: Part I. EXAFS studies of the geometry of coprecipitated and adsorbed arsenate. Geochim. Cosmochim. Acta 57: 2251-2269.

Yu, G., Saha, U. K., Kozak, L. M. and Huang, P. M. 2006. Kinetics of $\mathrm{Cd}$ adsorption on aluminum precipitation products formed under the influence of tannate. Geochim. Cosmochim. Acta 70: 5134-5145.

Zhang, H. and Selim, H. M. 2005. Kinetics of arsenate adsorption-desorption in soils. Environ. Sci. Technol. 39: 6101-6108.

Zhang, J. and Stanforth, R. 2005. Slow adsorption reaction between arsenic species and goethite $(\alpha-\mathrm{FeOOH})$ : diffusion or heterogeneous surface reaction control. Langmuir 21: 2895-2901.

Zhao, H. and Stanforth, R. 2001. Competitive adsorption of phosphate and arsenate on goethite. Environ. Sci. Technol. 35: 4753-4757. 